\title{
Giant Appendicolith in Acute Exacerbation of Chronic Appendicitis: Case Report and Literature Review
}

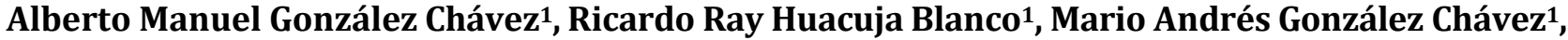 \\ Silviano Ríos Pascual ${ }^{1}$, Diego Abelardo Álvarez Hernández ${ }^{2}$, José de Jesús Curiel Valdés ${ }^{3}$ \\ ${ }^{1}$ Department of Surgery, Hospital HMG Coyocán, CDMX, México \\ ${ }^{2}$ Coordination of Medical Services, Mexican Red Cross I.A.P., CDMX, México \\ ${ }^{3}$ Pathology Laboratory, Grupo Diagnóstico, CDMX, México \\ Email: almagoch.md@gmail.com, riray@hotmail.com, Medicina00@gmail.com, silviano_rios@hotmail.com, \\ diego.alvarez.hernandez@hotmail.com, josecurielvaldes@hotmail.com
}

How to cite this paper: Chávez, A.M.G., Blanco, R.R.H., Chávez, M.A.G., Pascual, S.R., Hernández, D.A.Á. and Valdés, J.J.C. (2017) Giant Appendicolith in Acute Exacerbation of Chronic Appendicitis: Case Report and Literature Review. Surgical Science, 8, 457-463.

https://doi.org/10.4236/ss.2017.811051

Received: September 29, 2017

Accepted: November 13, 2017

Published: November 16, 2017

Copyright () 2017 by authors and Scientific Research Publishing Inc. This work is licensed under the Creative Commons Attribution International License (CC BY 4.0).

http://creativecommons.org/licenses/by/4.0/

\begin{abstract}
Right iliac fossa pain remains a challenge for clinicians, since it requires considering several differential diagnoses. Acute appendicitis continues to be one of the most important diagnoses to confirm or to rule out in acute abdominal pain, due to the associated morbidity and mortality. Currently, imaging studies contribute to increase diagnostic certainty, but sometimes reveal unexpected findings, which may further complicate the diagnosis and therapeutic decisions. We present the case of an unusual image finding in the right iliac fossa, a calcification suggestive of gallstone ileus, in the context of an acute abdomen with an unusual transoperative finding, whose definitive diagnosis by pathology, was also rare.
\end{abstract}

\section{Keywords}

Appendicolith, Fecalith, Chronic Appendicitis, Acute Abdomen, Abdominal Calcification, Acute Appendicitis

\section{Introduction}

Although acute appendicitis remains as the most frequent abdominal emergency surgery, its diagnosis is a challenge for clinicians [1]. Physiopathological principle to explain most cases of acute appendicitis is appendiceal lumen obstruction either by lymphoid hyperplasia, appendicoliths, tumors or foreign bodies. All these, rise intraluminal pressure, collapse lymphatic vessels, constipate veins, decrease arterial flow and, consequently, lead to necrosis and perforation [2] [3]. 
On the other hand, there are many causes for calcifications in the right iliac fossa: Gallstone ileus, renal or extruded vesical calculi, phlebolith, calcified uterine fibroid tumor, lithopedion, genitourinary tract calcifications, ovarian tumors, rejected renal allograft, calcified lymphatic ganglia, foreign bodies or radiologic artifact [4] [5].

Diagnosis would be determined by the clinician's experience, and if an unexpected finding comes out in image studies (like a right iliac fossa calcification), the accompanying signs and symptoms will determine the next step in the diagnostic approach. In the particular case of the Surgeon who evaluates an abdominal pain, these findings will make it even more complicated the decision of who should undergo a surgical procedure.

A case of a giant calcification at the right iliac fossa is presented, within the context of an acute abdomen.

\section{Case Presentation}

A 36-year-old female patient with a history of hyperthyroidism under management with thiamazol and propranolol, came to the emergency department, with a colicky abdominal pain of 48 hours of evolution, located in periumbilical region at the beginning, but migrating until reaching the right iliac fossa. It is accompanied by hyporexia and nausea. She reported having presented similar episodes of pain, which she attributed to colonic problems. These episodes resolved without specific management.

Physical examination detected her slightly hypertensive, other vital signs were normal. Heart sounds and lung fields were reported unaltered. The abdomen was distended, painful to the deep palpation of the right quadrants, and with clear peritoneal irritation signs (painful McBurney's point, positive VonBlumberg, Rosving and Dunphy signs).

Considering physical examination results, general lab tests were required. White cell count showed discrete leukocytosis $\left(12.7 \times 10^{9} / \mathrm{L}\right)$ and neutrophilia (85\%). Liver function tests, pancreatic enzymes, or general urine analysis were not altered. Abdominal tomography with intravenous contrast was requested where no pneumobilia or renal dilatation was documented (Figure 1). Both ureters had normal morphology. Bowel loop dilatation, cul-de-sac free fluid, and inflammatory pericecal ganglia of more than $10 \mathrm{~mm}$, were observed. Cecal appendix was $19 \mathrm{~mm}$ in diameter in its major axis and with a fecalith inside $(2.2 \times$ $1.6 \mathrm{~cm})$.

A broad-spectrum antibiotic (Amoxicillin-clavulanate) coverage was initiated, and the patient underwent diagnostic laparoscopy, where it could be observed: considerable inflammatory fluid $(230 \mathrm{~mL})$ in cursive, a retroileal appendix covered by a layer of fibrin and very increased in size towards its base. It was dissected with harmonic scalpel, closing its base with endoloops. Patient was discharged 36 hours after admission, without pain, normal blood count and adequate oral tolerance. 
The histopathological study reported a cecal appendix of $1.7 \mathrm{~cm}$ in its greater diameter with changes compatible with chronic appendicitis and periapendicitis, with zones of acute appendicitis secondary to a fecalith of $2 \mathrm{~cm}$ diameter (Figure 2).

\section{Discussion}

Fecaliths are fecal matter conglomerates with mineral deposits formed within intestinal lumen. They are presented in about $3 \%$ in the general population. Some cases of intestinal occlusion due to fecaliths have been described in ileum [6], cecum [7] or even in rectum [8]. Fecaliths in colonic diverticula have also been mentioned to increase the possibility of inflammation and perforation.

An appendicolith is formed when a fecalith hosts in cecal appendix lumen. It represents a well-known cause of acute appendicitis and a reason of intermittent chronic abdominal pain [9]. It was Fitz, who since 1886, identified them as a major cause in the inflation of the appendix [10]. In several trials, appendicoliths have been reported as the cause of $20 \%-40 \%$ acute appendicitis. This usually occurs in male patients under 35 years of age, who have a retrocecal appendix location [11] [12] [13]. Commonly, appendicolith measures less than $1 \mathrm{~cm}$ in diameter. They are called giant appendicoliths when they measure more than 2 $\mathrm{cm}$, and are extremely rare [14] [15]. The largest appendicolith reported in literature was $3.5 \mathrm{~cm}$ in diameter in a patient with Crohn disease and stump appendicitis [16].

A particular fact in relation to appendicoliths is that these are responsible of most cases of "stump appendicitis". This is because of two reasons: 1) the presence of a fecalith in the beginning of the appendix that is being resected, causes a misidentification of the base, leaving the fecalith retained with its consequent inflammation hours later or 2) a newly formed fecalith, which is impacted by a long appendicular stump ( $>5 \mathrm{~mm}$ ), obstructs and become inflamed [17].

On the other hand, the relationship between appendicoliths and chronic appendicitis is well established. It is induced by partial obstructions in appendicular lumen that are solved spontaneously. Its incidence is about $1.5 \%$ in the general population. Laparoscopic appendectomy is recommended by some authors in chronic abdominal pain cases, where an appendicolith is evident with any image method [18] [19].

In several studies, appendicoliths were suggested as $100 \%$ specific for the diagnosis of acute appendicitis [20] [21] however, further reports demonstrated the possibility of appendicoliths without acute appendicitis [22] [23] [24]. Their finding in a tomography has a $65 \%$ sensibility, $86 \%$ specificity and a $74 \%$ positive predictive value for acute appendicitis diagnosis [21]. That is, if a appendicolith is associated to abdominal pain, an acute appendicitis possibility is almost $90 \%$ and the risk of gangrenous appendicitis and early appendicular perforation is more than $50 \%$, especially if it measures more than $5 \mathrm{~mm}$ in diameter and is located at the base of the appendix [15] [25] [26]. 


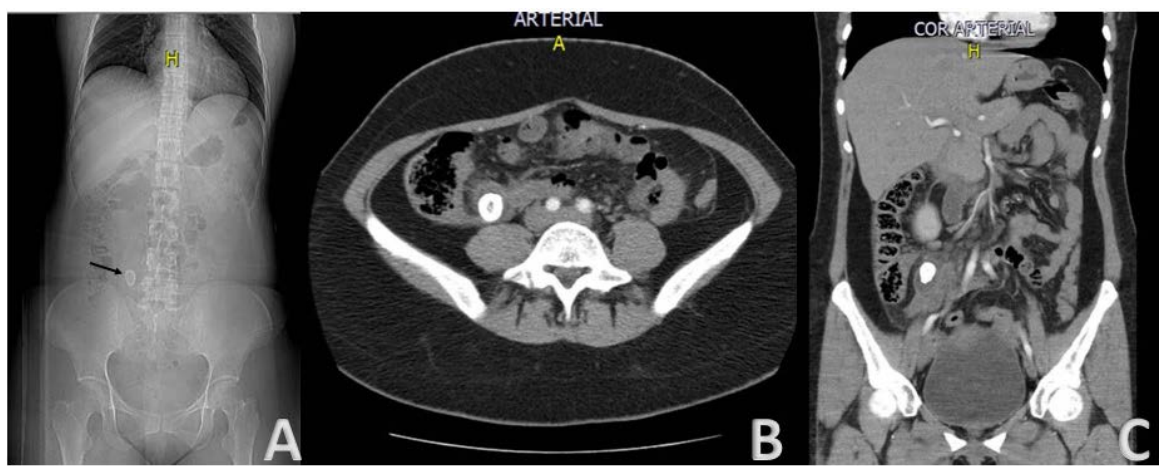

Figure 1. Axial contrasted computed tomography of the abdomen. (A) Topogram showing calcification in right iliac fossa; (B) axial view, where calcification next to cecum, can be seen; (C) abdomen coronal reconstruction that shows calcification within a tubular structure.
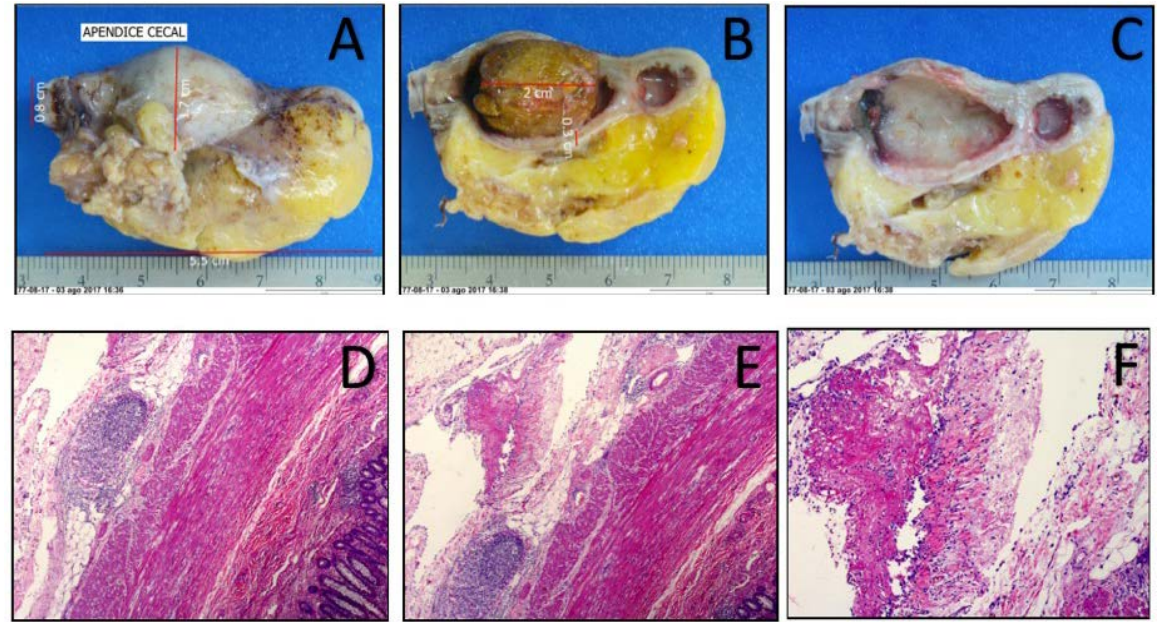

Figure 2. Cecal appendix macro and microscopic photographs. (A) Cecal appendix of 1.7 $\mathrm{cm}$ in diameter. Mesoappendix with layer of fibrin (B) Giant appendicolith in situ, $2 \mathrm{~cm}$ in diameter; (C) cavity formed by the appendicolith and tissular brick towards the tip of the appendix; (D) chronic periappendicitis [H\&E 10X]; (E) acute periappendicitis [H\&E $10 \times]$; F) acute Inflammatory infiltrate in detail [H\&E 20×].

The presence of a giant appendicolith can lead to diagnostic confusions, as in several cases reported in the literature, such as ureteral lithiasis, ovarian pathology and biliary ileus. These confusions delay diagnosis and increase associated morbidity and mortality risks [27] [28] [29] [30].

Most cases of giant appendicoliths reported in literature ( $>95 \%)$, have been handled with open surgery or endoscopic resection [31] [32]. Open approach is preferred at the risk of losing fecalith in cavity with resulting hepatic, abdominal or retroperitoneal abscess formation [33] [34] [35] [36]. Few cases have been solved successfully with conservative treatment in asymptomatic patients [14].

In the case presented here, a gallstone ileus was suggested as a first diagnostic possibility. However not all signs of Rigler's triad were fulfilled (pneumobilia, bowel obstruction, ectopic gallstone) and gallbladder was normal in the tomography. Diagnostic laparoscopy was justified by peritoneal irritation and leuko- 
cytosis. Surgery findings were in agreement with an acute appendicitis. Procedure was achieved by laparoscopy, and giant appendicolith suspicion was then confirmed, identifying the base of the appendix properly. Retrospectively, pathologists' analysis was a relevant contribution for the precise diagnostic. There were eosinophils and lymphocytes infiltrated areas which mean chronicity and polymorphonuclears infiltrated on wall areas which mean acute inflammation. Besides, recurrent episodes of abdominal pain, allowed the last piece of the puzzle elucidation.

Right iliac fossa pain is a real challenge due to the differential diagnostic factors. Moreover, if patient is a woman, the challenge is even more complicated. And, if an unusual finding as giant calcification comes out in imaging studies, approach could be even more complex. This difficulty was expressed in this clinical case, emphasizing the importance of the clinic studies but considering all available diagnostic resources.

\section{References}

[1] Ferris, M., Quan, S., Kaplan, B., Molodecky, N., et al. (2017) The Global Incidence of Appendicitis: A Systematic Review of Population-Based Studies. Annals of Surgery, 266, 237-241. https://doi.org/10.1097/SLA.0000000000002188

[2] Flum, D.R. (2015) Acute Appendicitis-Appendectomy or the "Antibiotics First" Strategy. NEJM, 372, 1937-1943. https://doi.org/10.1056/NEJMcp1215006

[3] Petroianu, A. and Villar Barroso, T.V. (2016) Pathophysiology of Acute Appendicitis. JSM Gastroenterology \& Hepatology, 4, 1-4.

[4] Salahi, M., Patel, H. and Knuttinen, M.G. (2015) Calcified Pelvic Masses on Radiographs: A Case Report and Discussion. Internal Medicine, 54, 1451-1454. https://doi.org/10.2169/internalmedicine.54.4059

[5] Singh, H., Neutze, J.A. and Enterline, J.R. (2015) Abdominal Calcifications. In: Neutze, J.A., Enterline, J.R. and Singh, H., Eds., Radiology Fundamentals. Introduction to Imaging \& Technology, Springer, 157-162.

[6] Nyberg, S.L. and Sutherland, D.E. (2000) Fecalith Impaction of the Terminal Ileum in a Diabetic Transplant Recipient. The American Journal of Gastroenterology, 95, 3286-3287. https://doi.org/10.1111/j.1572-0241.2000.03304.x

[7] Mahajna, A. and Krausz, M.M. (2009) Ileocolic Intussusception in an Adult Patient Due to a Cecal Fecalith. IMAJ, 11, 58-59.

[8] Nigar, S., Sunkara, T., Culliford, A. and Gaduputi, V. (2017) Giant Fecalith Causing Near Intestinal Obstruction and Rectal Ischemia. Case Reports in Gastroenterology, 11, 59-63. https://doi.org/10.1159/000455186

[9] Grimes, C., Chin, D., Bailey, C., Gergely, S., et al. (2010) Appendiceal Faecaliths Are Associated with right Iliac Fossa Pain. Annals of the Royal College of Surgeons of England, 92, 61-64. https://doi.org/10.1308/003588410X12518836439524

[10] Fitz, R.H. (1886) Perforating Inflammation of the Vermiform Appendix. The American Journal of the Medical Sciences, 92, 321-346.

[11] Engin, O., Muratli, A., Ucar, A.D., Tekin, V., et al. (2012) The Importance of Fecaliths in the Aetiology of Acute Appendicitis. Chirurgia, 107, 756-760.

[12] Singh, J.P. and Mariadason, J.G. (2013) Role of the Faecolith in Modern-Day Appendicitis. Annals of the Royal College of Surgeons of England, 95, 48-51. 
https://doi.org/10.1308/003588413X13511609954851

[13] Kaya, B. and Eris, C. (2011) Different Clinical Presentation of Appendicolithiasis. The Report of Three Cases and Review of the Literature. Clinical Medicine Insights: Pathology, 4, 1-4. https://doi.org/10.4137/CPath.S6757

[14] Scroggie, D.L. and Al-Whouhayb, M. (2015) Asymptomatic Giant Appendicolith Managed Conservatively. Journal of Surgical Case Reports, 11, 1-3. https://doi.org/10.1093/jscr/rjv149

[15] Ishiyama, M., Yanese, F., Taketa, T., Makidono, A., et al. (2013) Significance of Size and Location of Appendicoliths as Exacerbating Factor of Acute Appendicitis. Emergency Radiology, 20, 125-130. https://doi.org/10.1007/s10140-012-1093-5

[16] Keating, J.P. and Memon, S. (2005) Giant Appendicolith. Gastrointestinal Endoscopy, 61, 292-293. https://doi.org/10.1016/S0016-5107(04)02547-7

[17] Mínguez, G., Gonzalo, R., Tamargo, A., Turienzo, E., et al. (2013) An Unsuspected Clinical Condition: Appendicitis of Appendicular Residual, Three Cases Report. International Journal of Surgery Case Reports, 4, 371-374. https://doi.org/10.1016/j.ijscr.2013.01.026

[18] Pandža, H., Čustović, S., Čović, R., Delibegovic, S., et al. (2008) Laparoscopic Treatment of Lower Abdominal Pain Related to Chronic Appendicitis. Medicinski Arhiv, 62, 268-270.

[19] Mattei, P., Sola, J.E. and Yeo, C.J. (1994) Chronic and Recurrent Appendicitis Are Uncommon Entities Often Misdiagnosed. Journal of the American College of Surgeons, 178, 385-389.

[20] Kim, D., Butterworth, S.A. and Goldman, R. (2016) Chronic Appendicitis in Children. Canadian Family Physician, 62, e304-e305.

[21] Rao, P.M., Eittenberg, J., McDowell, R.K., Rhea, J.T., et al. (1997) Helical Computed Tomographic Incidence and Characterization of Appendoliths in 100 Patients with Appendicitis. Emergency Radiology, 4, 55-61. https://doi.org/10.1007/BF01508029

[22] Lowe, L.H., Penney, M.W., Scheker, L.E., Perez, R., et al. (2000) Appendicolith Revealed on CT in Children with Suspected Appendicitis: How Specific Is It in the Diagnosis of Appendicitis? AJR American Journal of Roentgenology, 175, 981-984.

[23] Huwart, L., El Khoury, M., Lesavre, A., Phan, C., et al. (2006) Le stercolithe est-il un signe fiable d'appendicite? [Is Appendicolith a Reliable Sign for Acute Appendicitis at MDCT?] Journal de radiologie, 87, 383-387.

[24] Ramdass, M.J., Sing, Q.Y., Milne, D., Mooteeram, J., et al. (2015) Association between the Appendix and the Fecalith in Adults. Canadian Journal of Surgery, 58, 10-14. https://doi.org/10.1503/cjs.002014

[25] Rabinowitz, C.B., Egglin, T.K., Beland, M.D. and Mayo-Smith, W.W. (2007) Outcomes in 74 Patients with an Appendicolith Who Did Not Undergo Surgery: Is Follow-Up Imaging Necessary? Emergency Radiology, 14, 161-165.

[26] Aladeen, D.I., Cook, M. and Chwals, W.J. (2008) Appendiceal Fecalith Is Associated with Early Perforation in Pediatric Patients. Journal of Pediatric Surgery, 43, 889-892. https://doi.org/10.1016/j.jpedsurg.2007.12.034

[27] Kondo, N.I. and Kohmo, H. (2009) Retained Appendicolith in an Inflamed Appendix. Emergency Radiology, 16, 105-109. https://doi.org/10.1007/s10140-008-0772-8

[28] Kumar, K. and Lewis, D. (2015) Diagnostic Confusion Caused by a Giant Appendicolith: A Case Report. Journal of Medical Cases, 6, 71-73. https://doi.org/10.14740/jmc2032w

[29] Akinkunmi, M. and Fadiran, O. (2009) Ruptured Acute Appendicitis with Calcified 
Appendicolith Mimicking Acute Gastroenteritis. Internet Journal of Health, 12, 1-5.

[30] Teke, Z., Kabay, B., Erbis, H. and Tuncay, O.L. (2008) Appendicolithiasis Causing Diagnostic Dilemma: A Rare Cause of Acute Appendicitis (Report of a Case). Turkish Journal of Trauma \& Emergency Surgery, 14, 323-325.

[31] VanWinter, J.T. and Beyer, D.A. (2004) Chronic Appendicitis Diagnosed Preoperatively as an Ovarian Dermoid. Journal of Pediatric \& Adolescent Gynecology, 17, 403-406. https://doi.org/10.1016/j.jpag.2004.09.011

[32] Igwe, P.O. and Okpani, C.O. (2015) Giant Calculus of the Appendix-Report of Three Cases. Gazette of Medicine, 4, 382-386.

[33] Kim, D.J., Park, S.W., Choi, S.H., Lee, J.H., et al. (2014) A Case of Endoscopic Removal of a Giant Appendicolith Combined with Stump Appendicitis. Clinical Endoscopy, 47, 112-114. https://doi.org/10.5946/ce.2014.47.1.112

[34] Singh, A.K., Hahn, P.F., Gervais, D., Vijayraghavan, G., et al. (2008) Dropped Appendicolith: CT Findings and Implications for Management. AJR, 190, 707-711. https://doi.org/10.2214/AJR.07.2917

[35] Kumar, D., Ramanathan, S., Al Faki, A. and Nepal, P. (2015) Faecolith Migrating from the Appendix to Produce Liver Abscess after Subhepatic Laparoscopic Appendectomy. Tropical Doctor, 45, 241-244.

https://doi.org/10.1177/0049475515577749

[36] Gupta, N., Sapire, J.M., Marrinan, G., Bansal, I., et al. (2016) Some Stones Are Precious-Extraluminal Appendicoliths. Indian Journal of Surgery, 78, 507-508.

https://doi.org/10.1007/s12262-016-1550-6 